\title{
Characterization of etoposide- and cisplatin-chemoresistant retinoblastoma cell lines
}

\author{
MAIKE BUSCH $^{1 *}$, DAVID PAPIOR ${ }^{1 *}$, HARALD STEPHAN $^{2}$ and NICOLE DÜNKER ${ }^{1}$ \\ ${ }^{1}$ Institute of Anatomy II, Department of Neuroanatomy, University of Duisburg-Essen; \\ ${ }^{2}$ Division of Haematology and Oncology, Children's Hospital, University of Duisburg-Essen, D-45122 Essen, Germany
}

Received August 23, 2017; Accepted October 27, 2017

DOI: $10.3892 /$ or.2017.6100

\begin{abstract}
Retinoblastoma (RB) is the most common malignant intraocular tumor in early childhood. Imminent chemotherapy resistance diminishes the clinical-therapeutic options and emphasizes the necessity for new therapeutic approaches. The present study aimed at characterizing and comparing etoposide and cisplatin-resistant human RB cell lines with regard to changes in proliferation and apoptosis levels, anchorage independent growth behavior in vitro as well as tumor formation capacity in vivo. The proliferation rates were significantly increased in the etoposide-resistant RB cell lines Y-79, WERI-Rb1 and RB-355 reflecting significantly higher growth kinetics compared to the parental controls. In line with these findings in in vivo chicken chorioallantoic (CAM) assays, etoposide-resistant cell lines generated significantly increased numbers of tumors with higher tumor weights compared to their parental counterparts. In contrast to etoposide, the cisplatin-resistant RB cell lines Y-79, WERIRb1 and RB-355 displayed significantly increased apoptosis rates and reduced proliferation rates resulting in significantly decreased growth kinetics. Tumor formation capacity of cisplatin-resistant cell lines did not significantly change, and in comparison with parental controls cisplatin-resistant Y-79 cells displayed significantly reduced tumor weight. Soft agarose assays indicated that anchorage-independent growth of all chemotherapy-resistant cell lines analyzed was significantly decreased. Summarizing, one can state that etoposide-resistant RB cells behave more aggressively than the tumor cells of origin and potentially represent a risk factor for local relapse, while cisplatin-resistant cells show a significantly decreased tumorigenic potential.
\end{abstract}

Correspondence to: Professor Nicole Dünker,Institute of Anatomy II, Department of Neuroanatomy, University of Duisburg-Essen, Medical Faculty, Hufelandstr 55, D-45122 Essen, Germany

E-mail: nicole.duenker@uk-essen.de

*Contributed equally

Key words: retinoblastoma, chemoresistance, tumor formation, growth, apoptosis, proliferation, chorioallantoic membrane assay

\section{Introduction}

Retinoblastoma (RB) is the most common intraocular malignant neoplasm of infancy and childhood. Although enucleation is an effective therapy for children with RB, one has to consider the resulting visual impairment and cosmetic deformity. External beam radiation therapy (EBRT) was proven to be the first effective eye salvage therapy for advanced RB, but it increased the risk of secondary tumors in children with germline $R B 1$ mutations [for review see (1)]. In the 1990s, systemic chemotherapy with focal therapy (laser and cryotherapy) was the standard treatment for intraocular RB (1). Intra-arterial chemotherapy (IAC), delivered via the internal carotid artery, was first used to enhance the effectiveness of EBRT, but is now a standard primary treatment in ocular centers to avoid enucleation or systemic treatment and a second-line therapy after failure of intravenous chemoreduction (1-3). To date, ophthalmic artery chemosurgery and intravitreous chemotherapy have completely replaced EBRT, reduced the use of systemic chemotherapy and diminished enucleations $(2,3)$.

DNA topoisomerase (topo) enzymes regulate DNA metabolism and affect replication, transcription, recombination, chromatin assembly, DNA repair and ultimately cell division. Important chemotherapeutic agents target these enzymes. Inhibitors of topo II enzymes, such as etoposide, stabilize DNA-topo II complexes by blocking DNA relegation. Trapping the enzyme in a complex with cleaved DNA causes direct double-strand DNA damage that then leads to p53 stabilization, finally causing apoptosis $(4,5)$.

The DNA-damaging agent cisplatin is likewise used extensively as a chemotherapeutic drug. Since 1994 chemotherapy with cisplatin and vincristine combined with focal therapy has been successfully used for RB treatment. Cisplatin acts as an alkylating or chelating agent, capable of forming adducts with macromolecules such as cellular DNA. This results in DNA cross-links and induces cell cycle arrest (6). The inability to repair the DNA damage ultimately mediates the cytotoxicity of this anticancer agent.

Another commonly used drug regiment includes a combination of vincristine, etoposide and carboplatin (VEC) for intravenous administration (7). However, management of RB is limited not only by drug dosage-related side-effects, but also by drug resistance to chemotherapy. Resistance to chemotherapy leading to poor outcome and survival remains 
a challenge for developing strategies for therapeutic interventions in all types of cancer and in vitro chemoresistant cell line models are an indispensable resource towards delineating the development of novel drugs.

In the present study, we set out to characterize three etoposide- and three cisplatin-resistant RB cell lines with regard to morphological and functional changes compared to their respective parental, chemosensitive counterparts.

\section{Materials and methods}

Cell culture. The human RB cell line RB-355, established and first described by Griegel et al (1990) (8), and formerly donated by K. Heise, was kindly provided by Dr H. Stephan. The RB cell lines Y-79 (9) and WERI-Rb1 (10), originally purchased from the Leibniz Institute DSMZ (German Collection of Microorganisms and Cell Cultures), were likewise kindly provided by Dr H. Stephan. All RB cell lines were last tested and authenticated in September 2015. Mutation analyses were conducted using an MLPA kit (SALSA MLPA kit P047 RB1; MRC-Holland, Amsterdam, The Netherlands) and reactions were performed according to the manufacturer's instructions. Additional sequencing of the $R B I$ gene was performed for all RB cell lines. However, most recent STR analyses (March 2017) confirmed the authenticity of the cell lines.

The cell lines were cultivated as suspension cultures in Dulbecco's modified Eagle's medium (DMEM) with 15\% fetal bovine serum (FBS) (both from PAN-Biotech $\mathrm{GmbH}$, Aidenbach, Germany), $100 \mathrm{U}$ penicillin/ml and $100 \mu \mathrm{g}$ streptomycin/ml, 4 mM L-glutamine (both from Gibco, Karlsruhe, Germany), $50 \mu \mathrm{M} \beta$-mercaptoethanol (Carl Roth, Karlsruhe, Germany) and $10 \mu \mathrm{g}$ insulin/ml (PAN-Biotech) at $37^{\circ} \mathrm{C}, 10 \%$ $\mathrm{CO}_{2}$ and $95 \%$ humidity. No approval from an Ethics Committee was required for work with the human cell lines.

Chemoresistant RB cell lines. All chemoresistant RB cell lines characterized were generously provided by Dr H. Stephan. To generate these cell lines, established Y-79, WERI-Rb1 and RB-355 cells (see above) were continuously treated with consecutively increasing concentrations of etoposide or cisplatin (both from Teva, Berlin, Germany) until the chemoresistant sublines exhibited a at least 10 -fold higher $\mathrm{IC}_{50}$ value in WST-1 viability assays than the respective parental controls (11). The chemoresistant cell lines were subsequently cultivated as described above for RB cell lines with additional treatment of the appropriate cytostatic drug twice a week (every 3-4 days). For details on final concentrations of the drugs used, see Table I.

Cell proliferation and apoptosis detection. Cell proliferation was determined by 5-bromo-2'-deoxyuridine (BrdU; Sigma, Steinheim, Germany) incorporation. For BrdU immunocytochemistry $10 \mu \mathrm{M}$ BrdU was added to the cells $4 \mathrm{~h}$ prior to paraformaldehyde (PFA; Sigma) fixation. Cells were incubated with a rat anti-BrdU antibody (1:1,000; ab6326; Abcam, Cambridge, UK) and proliferating cells were visualized using a goat anti-rat antibody labelled with Alexa Flour ${ }^{\circledR} 488$ (1:1,000; A11006; Life Technologies, Darmstadt, Germany). In order to determine changes in apoptosis levels, cells were stained with 4',6-diamidino-2-phenylindole (DAPI; Sigma)
Table I. Concentrations of the chemotherapeutic agents used to treat the RB cell lines.

\begin{tabular}{llc}
\hline Cytostatic drug & Cell line & $\begin{array}{r}\text { Final concentration } \\
(\mu \mathrm{mol} / \mathrm{ml})\end{array}$ \\
\hline Cisplatin & WERI-Rb1 & 8 \\
$(1 \mathrm{mg} / \mathrm{ml})$ & Y-79 & 5 \\
& RB-355 & 6 \\
Etoposide & WERI-Rb1 & 5 \\
$(20 \mathrm{mg} / \mathrm{ml})$ & Y-79 & 3 \\
& RB-355 & 1 \\
\hline
\end{tabular}

or Click-iT ${ }^{\circledR}$ Plus TUNEL assay for in situ apoptosis detection (cat. \#C10617; Thermo Fisher Scientific, Darmstadt, Germany), following the manufacturer's protocol and pycnotic nuclei were manually counted as previously described by our group (12).

Growth kinetic. To determine growth kinetics, $3 \times 10^{5} \mathrm{RB}$ cells were seeded in $500 \mu \mathrm{l}$ DMEM with supplements in a 24-well plate and vital cells were counted manually using the trypan blue exclusion method. Cells were seeded in triplicates and counted at several time points $(24,48,72$ and $96 \mathrm{~h})$. In the case of the extremely slow-growing Y-79 cisplatin-resistant RB cell line, we recorded long-term growth curves over a period of $336 \mathrm{~h}$ with longer counting intervals and plotted the values logarithmically to visualize differences between resistant and control cells.

Colony formation assay. Soft agarose assays were performed as previously described in detail (13). The colony formation efficiency $(\%) /$ visual field was determined by counting the colonies and single cells in 5 visual fields (magnification, x10)/cell line in triplicates and images were captured using a Leica DMIL or a Nikon Eclipse TS2 microscope equipped with a digital camera and ProgRes Capture Basic 1.2.01 or IC Capture 2.4 (The Imaging Source) software.

Chicken chorioallantoic (CAM) assays. In order to test for changes in the migration and tumor formation capacity following etoposide and cisplatin resistance, RB cells were grafted onto the chick chorioallantoic membrane (CAM) as described in a recent publication by our group (14). Mainly following the metastasis model protocol published by Zijlstra et al (2002) (15), and visualized by Palmer et al (2011) (16), $50 \mu \mathrm{l}$ cell suspension $\left[1 \times 10^{6}\right.$ chemoresistant or control cells in phosphate-buffered saline (PBS)] was grafted onto the CAM area. For each RB cell line, 30 eggs were grafted ( 15 with parental and 15 with chemoresistant RB cells) in at least 3 independent experiments. All in vivo chick CAM experiments were conducted according to the relevant national guidelines of the responsible authority, the State Office for Nature, Environment and Consumer Protection (LANUV) as well as to the Directive 2010/63/EU of the European Parliament and of the council of September 22, 2010 on the protection of animals used for scientific purposes, which does not comprise 
any restrictions for the use of non-mammalian embryos. However, the Institutional Animal Care and Use Committee (IACUC) of the Medical Faculty of the University Hospital Essen approved the CAM assays and no ethical approval was required as according to the German Animal Experiment and Welfare Guidelines, ethical approval is only essential when animals are intended to live beyond hatching.

Harvesting of tissue. The duration of the chick CAM assay is limited to a 7-9 day window prior to hatching. Seven days after grafting (E10-17) chick embryos were anesthetized by cooling on ice and sacrificed by decapitation. CAM tumors were excised, measured, photographed and fixed for $1 \mathrm{~h}$ at $4^{\circ} \mathrm{C}$ in $4 \%$ PFA in $0.1 \mathrm{M}$ phosphate buffer ( $\mathrm{pH} 7.4$ ). For cryoembedding, the tumor tissue was incubated for $30 \mathrm{~min}$ in PBS (pH 7.3) containing $15 \%$ sucrose, followed by a $30-\mathrm{min}$ incubation in PBS containing 30\% sucrose and finally embedded in OCT compound (Tissue-Tek; Germany), and sectioned at $10 \mu \mathrm{m}$ using a cryostat. Images and measurements of tumors forming on the upper CAM were captured with a Nikon stereo dissecting microscope SMZ 1000 equipped with a Nikon digital camera and Nikon EclipseNet software. Exemplarily, images were captured with a 3D-Profilomter VR-3200 microscope (Keyence, Neu-Isenburg, Germany) to visualize changes in the $3 \mathrm{D}$ volume of the tumors.

Immunocytochemistry. The localization of the tumors forming in the upper CAM after grafting was visualized on hematoxylin and eosin (H\&E)-stained cryosections. The human origin of the tumors forming in the chicken CAM after grafting human RB cells was verified using a mouse anti-human nuclear antibody (MAB 128; Merck Millipore, Darmstadt, Germany) at a dilution of 1:100 in PBS containing 0.1\% Triton, $4 \%$ bovine serum albumin (BSA) and $1 \%$ normal goat serum (NGS) overnight at $4{ }^{\circ} \mathrm{C}$. The reaction was visualized using a goat anti-mouse antibody labelled with Alexa Flour $^{\circledR} 488$ (A11001; Molecular Probes, Camarillo, CA, USA), diluted 1:1,000 in PBS with $1 \%$ BSA for $2 \mathrm{~h}$ at room temperature.

For $\beta$-tubulin stainings, $1 \times 10^{5}$ cells were stained on coverslips as previously described (17). In brief, cells were fixed with 4\% PFA in PBS for $1 \mathrm{~h}$ following 3 washes with PBS. Afterwards, cells were incubated with ice-cold $100 \%$ methanol for 5 min on ice, washed 3 times with PBS and incubated for $1 \mathrm{~h}$ in blocking solution [PBS, $0.3 \%$ Triton, $4 \%$ BSA, 5\% NGS (Dako, Hamburg, Germany)]. Anti $\beta$-tubulin primary antibody (T-4026; Sigma-Aldrich, Munich, Germany) was diluted 1:200 in PBS containing 0.1\% Triton, 4\% BSA and 1\% NGS and cells were incubated overnight at $4^{\circ} \mathrm{C}$. Following 3 washes with PBS, goat anti-mouse secondary Alexa 488-coupled antibody (Molecular Probes, Germany) was used at 1:1,000 dilutions in PBS/1\% BSA (Roth). Finally, cells were counterstained with DAPI to visualize the nucleus. As controls, in all cases PBS was substituted for the primary antisera in order to test for non-specific labeling. No specific cellular staining was observed when the primary antiserum was omitted.

Measurements of cell and nuclear size. For measurements of cell and nuclear sizes, images from $\beta$-tubulin-stained cells on coverslips were acquired using a Nikon Eclipse E600 microscope equipped with a digital camera. For each cell line,
5 equally distributed, $x$-shape rendered visual fields/coverslip were captured, and the cytoplasmic and nuclear outline of 7 cells/visual field were measured using the Nikon Eclipse net measurement software.

Statistical analysis. All assays were performed at least in triplicate. Statistical analyses were conducted using GraphPad Prism 6. Data represent means \pm SEM of 2 to 5 independent experiments from independent RB cell cultures. Results were analyzed by a Students t-test or one-way ANOVA and Newman-Keuls post hoc test and considered significantly different at ${ }^{*} \mathrm{P}<0.05,{ }^{* *} \mathrm{P}<0.01$ or ${ }^{* * *} \mathrm{P}<0.001$. Statistics on the growth curves was performed using a free web interface http:// bioinf.wehi.edu.au/software/compareCurves/, which uses the compareGrowthCurves-function from a statistical modeling package called 'statmod', available from the R Project for Statistical Computing: http://wwww.r-project.org, previously described elsewhere (18).

\section{Results}

Etoposide and cisplatin resistance changes $R B$ cell line morphology. In order to check for morphological changes following etoposide and cisplatin resistance, we compared the appearance of parental and chemoresistant Y-79, WERI-Rb1 and RB-355 cells a) in cell culture (Fig. 1A) and b) after seeding on poly-D-lysine-coated coverslips and immunocytochemical staining with $\beta$-tubulin and DAPI counterstaining (Fig. 1B). While all parental controls and particularly WERI-Rb1 cells frequently form chain-like structures when seeded on coverslips, all chemoresistant RB cell lines tended to form clusters, which were more pronounced in etoposide-resistant cell lines than in cisplatin-resistant cells. However, the etoposide- and cisplatinresistant cell lines seemed to become partially adherent and sometimes neurite-like processes could be observed.

Measurements of cell and nuclear size revealed that compared to their parental counterparts, cisplatin-resistant cells were significantly bigger and had larger nuclei (Fig. 2A and B), whereas etoposide-resistant cells did no exhibit significant changes in either size (data not shown).

Etoposide resistance significantly increases the growth and proliferation of RB cell lines. The etoposide-resistant cell lines Y-79 and WERI-Rb1, established from two well-established RB cell lines, originally derived from unilateral RB tumors (10), exhibited significantly higher growth rates compared to the parental etoposide-sensitive control cells (Fig. 3A and B). In semi-adherent RB-355 RB cells, likewise derived from an unilateral RB tumor, but exhibiting different growth kinetics (19), cell growth was not significantly affected by etoposide resistance (Fig. 3C).

As revealed by WST- 1 assays, etoposide resistance resulted in a significant increase in Y-79 cell viability. WERI-Rb1 etoposide-resistant cells displayed a slightly, but not significantly increased viability, whereas etoposide resistance did not significantly alter the viability of RB-355 cells compared to the parental controls (Fig. 3D).

Cell proliferation was significantly increased in all three etoposide-resistant RB cell lines analyzed as reflected by significantly higher numbers of BrdU-positive cells (Fig. 3E). 
A
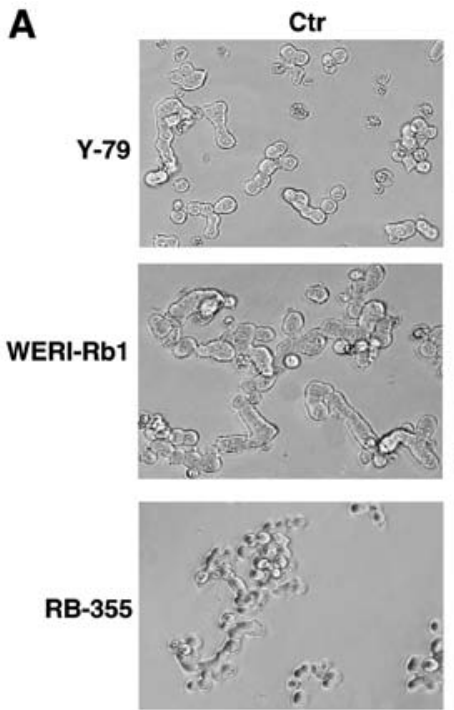

B
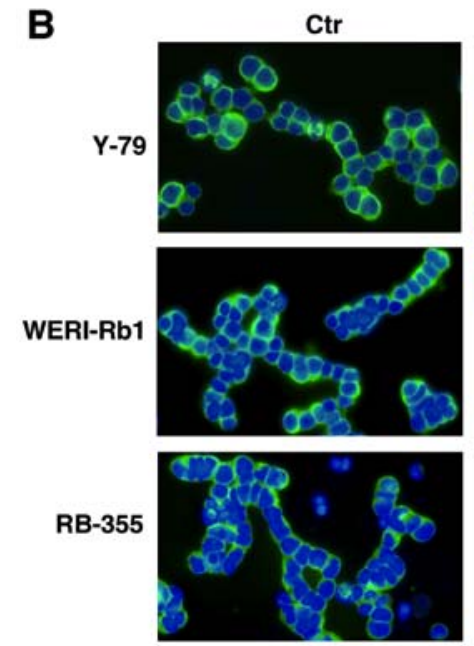
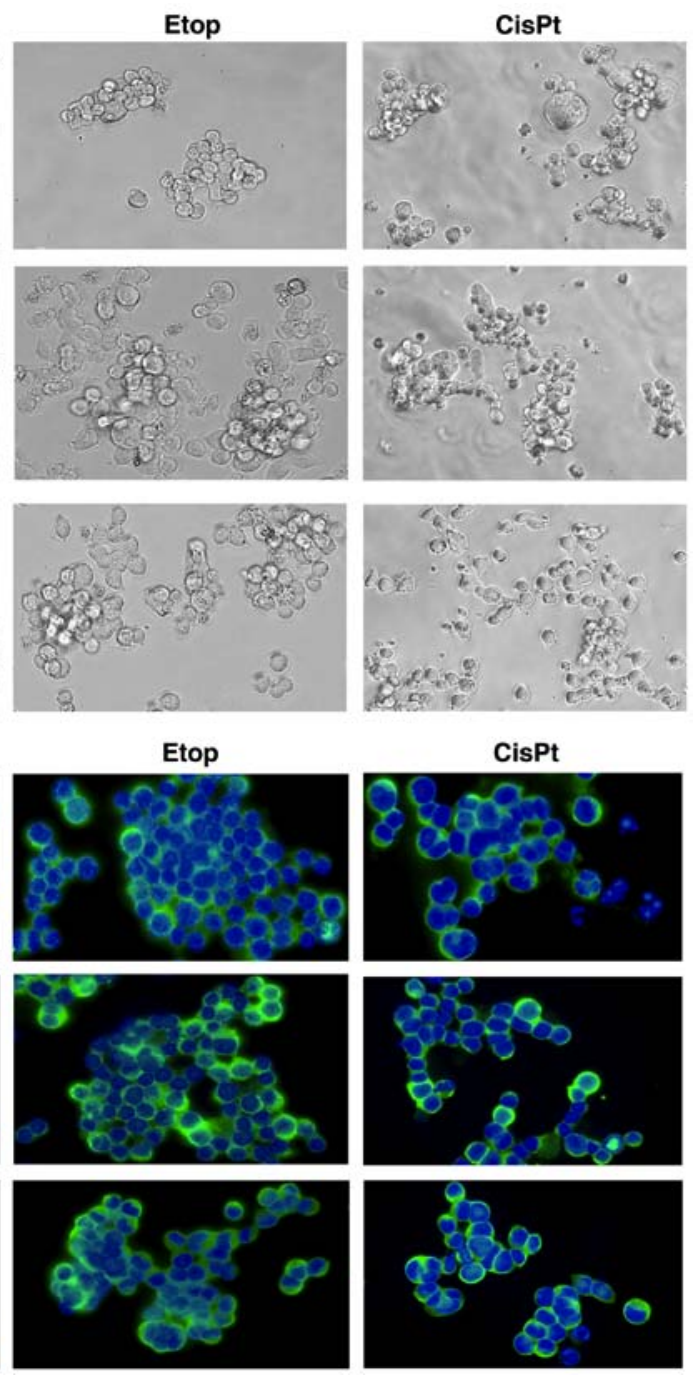

Figure 1. Effects of etoposide and cisplatin resistance on RB cell line morphology. (A) Images of parental (Ctr), etoposide (Etop) and cisplatin-resistant (CisPt) Y-79, WERI-Rb1 and RB-355 RB cells in culture. (B) Images of parental, etoposide- and cisplatin-resistant RB cell lines after seeding on coverslips and immunocytochemical staining with $\beta$-tubulin (green fluorescence) and DAPI counterstaining (blue fluorescence). Morphological comparison revealed that parental controls frequently form chain-like structures, whereas chemoresistant RB cell lines tend to form clusters.
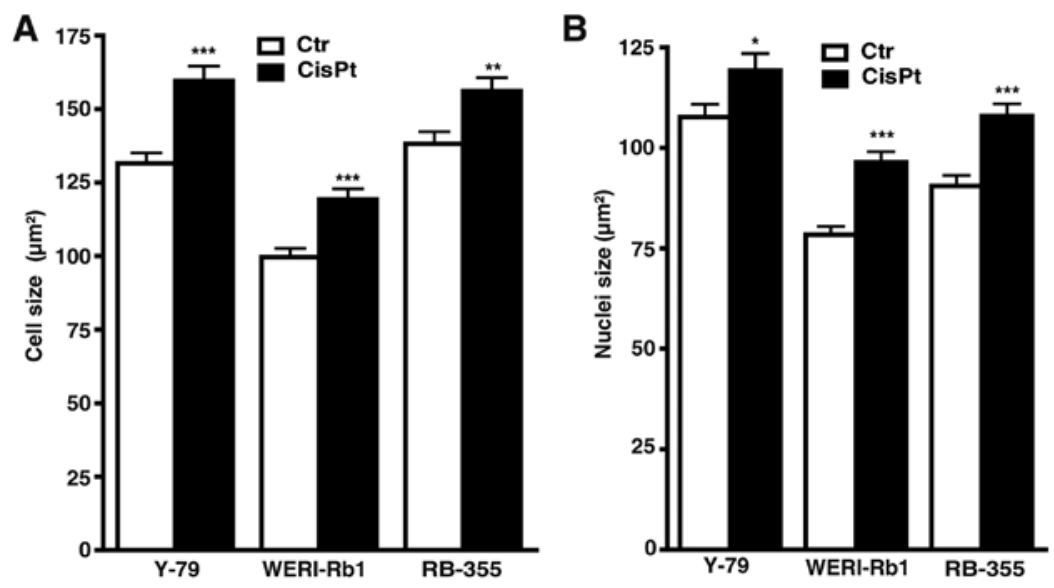

Figure 2. Changes in (A) RB cell and (B) nuclei size following cisplatin resistance. Compared to their parental counterparts (Ctr), cisplatin-resistant cells (CisPt) were significantly bigger $(\mathrm{A})$ and had larger nuclei $(\mathrm{B}) .{ }^{*} \mathrm{P}<0.05,{ }^{* *} \mathrm{P}<0.01,{ }^{* * *} \mathrm{P}<0.001$ statistical differences compared to the control group calculated by Student's t-test.

Etoposide treatment still induces apoptosis in etoposide-resistant RB cell lines. As revealed by DAPI cell counts (Fig. 3F) and confirmed by TUNEL assays (Fig. 4A) continuous treatment with etoposide still significantly induced 

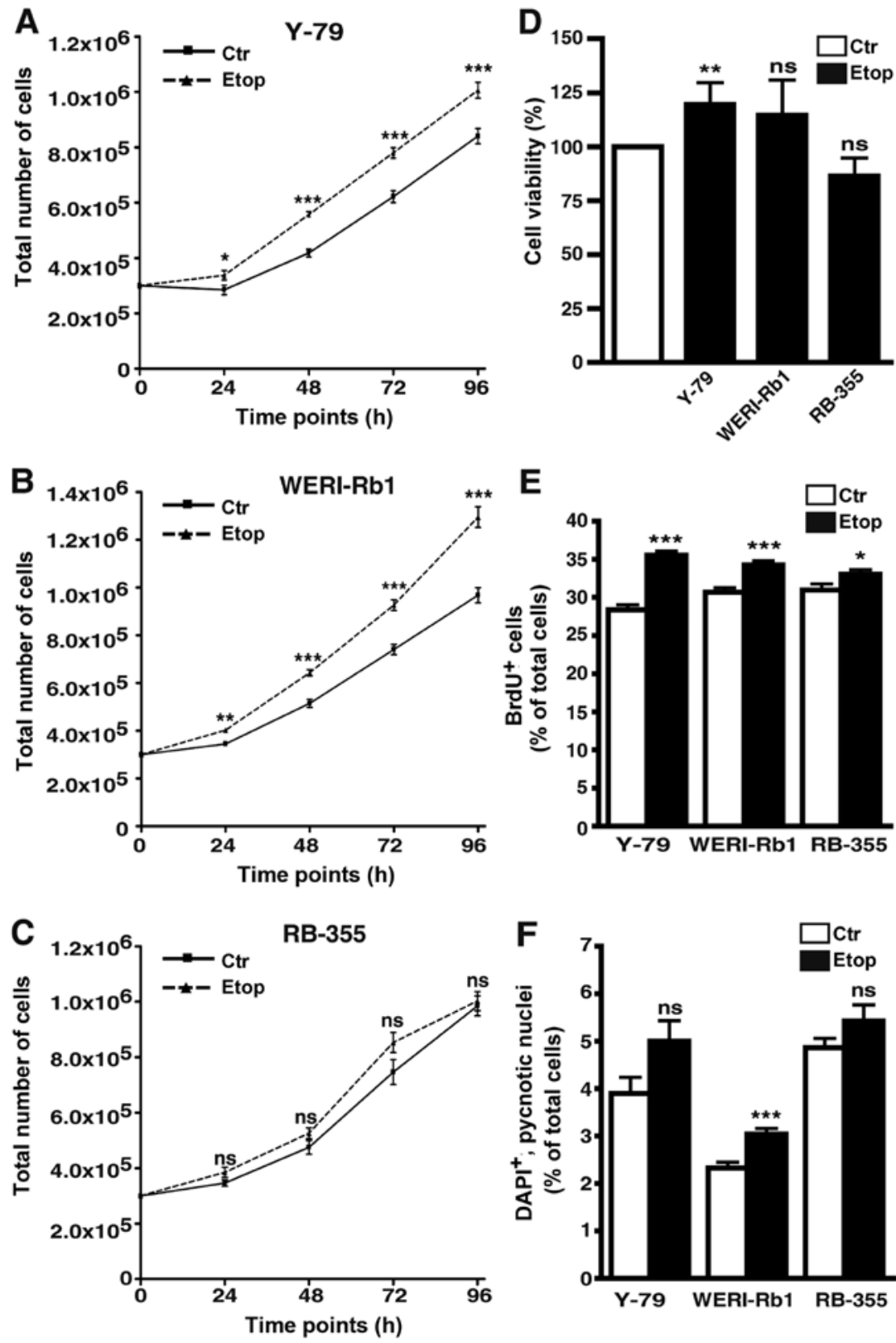

Figure 3. Effects of etoposide resistance on RB cell growth, viability, proliferation and apoptosis. (A-C) Growth curves, (D) WST-1 assays, (E) BrdU counts and (F) DAPI cell counts of etoposide-resistant (Etop) Y-79 (A), WERI-Rb1 (B) and RBL-355 cells (C) vs. control cells (Ctr) revealed that etoposide resistance led to a significant increase in growth kinetics of Y-79 and WERI-Rb1 cells (A and B). Accordingly, cell proliferation was significantly increased in all three etoposide-resistant cell lines (E). Values are means of at least 3 independent experiments $\pm \mathrm{SEM} ;{ }^{*} \mathrm{P}<0.05,{ }^{* *} \mathrm{P}<0.01,{ }^{* * * *} \mathrm{P}<0.001 ;$ ns, no statistical differences compared to the control group calculated by Student's t-test.

apoptosis in the WERI-RB1 etoposide-resistant RB cells, whereby the increase in cell death levels in the Y-79 and RB-355 etoposide-resistant cell lines was not significant. The remaining pro-apoptotic effect of etoposide seemed to counterbalance its pro-proliferative effect after induction of resistance (Fig. 3E) resulting in an absent overall effect of etoposide on cell viability in the WERI-Rb1 and RB-355 etoposide-resistant cells (Fig. 3D). By contrast, in Y-79 etoposide-resistant cells, displaying significantly increased cell viabilities (Fig. 3D), the strong pro-proliferative effect of etoposide-resistance appeared to predominate (Fig. 3E).

Etoposide resistance significantly increases the incidence, weight, and size of tumors developing from RB cell lines.
Photo-documentation (Fig. 5A and B), counts (Fig. 5C) and measurements of the tumors (Fig. 5D and E) developing from Y-79, WERI-Rb1 and RBL-355 cells grafted on the upper CAM revealed that the tumor formation capacity of Y-79 and WERI-Rb1 etoposide-resistant cell lines was significantly increased compared to their parental counterparts (Fig. 5C). Tumor formation capacity of semi-adherent RB-355 etoposide-resistant cells likewise increased, but did not reach significance. However, the etoposide-resistant RB cell lines developed larger tumors (Fig. 5D) and tumors of significantly higher weight (Fig. 5E) when compared with the chemosensitive control cells.

The localization of the tumors developing in the upper chicken CAM at the border between CAM ectoderm and 
A

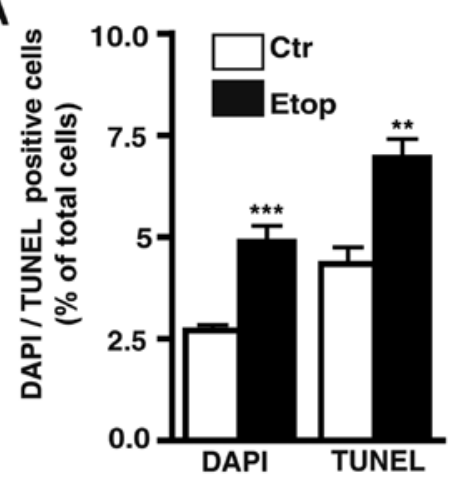

B

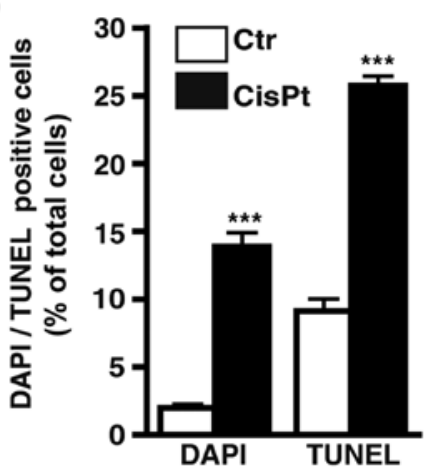

Figure 4. Effect of etoposide and cisplatin resistance on apoptosis levels in retinoblastoma cell lines. (A) Comparative quantification of DAPI and TUNEL cell counts of etoposide-resistant RB cell lines (Etop) compared to their parental counterparts (Ctr). (B) Comparative quantification of DAPI and TUNEL cell counts of cisplatin-resistant RB cell lines (CisPt) compared to their parental counterparts (Ctr). Values are means from 3 independent experiments \pm SEM; ${ }^{* *} \mathrm{P}<0.01,{ }^{* * *} \mathrm{P}<0.001$ compared to the control group calculated by Student's t-test.

A Y-79

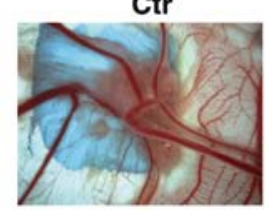

WERI-Rb1

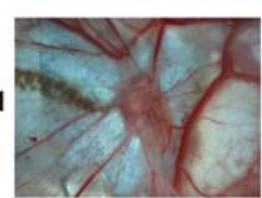

RB-355

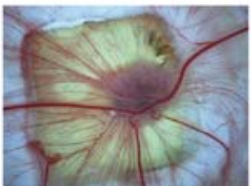

B

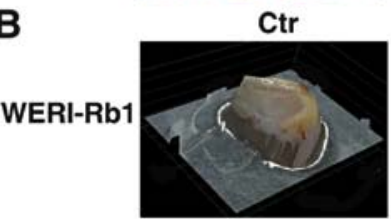

C

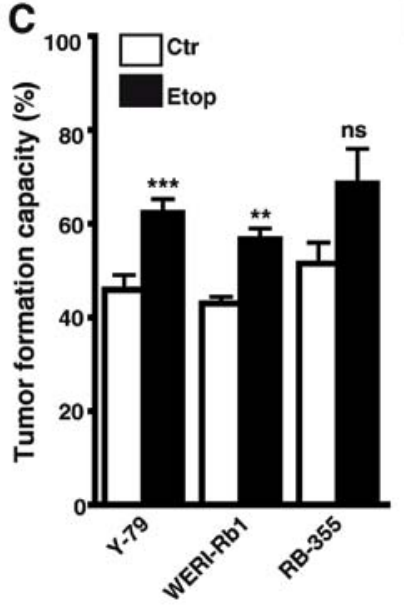

Etop
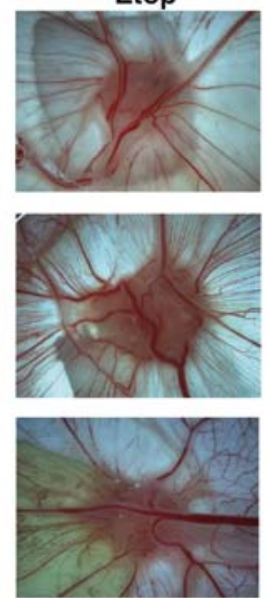

Etop
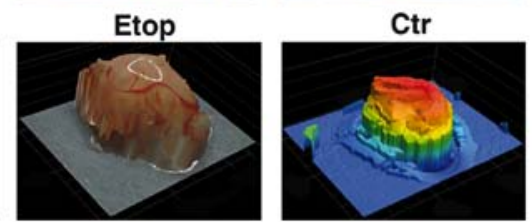

Etop
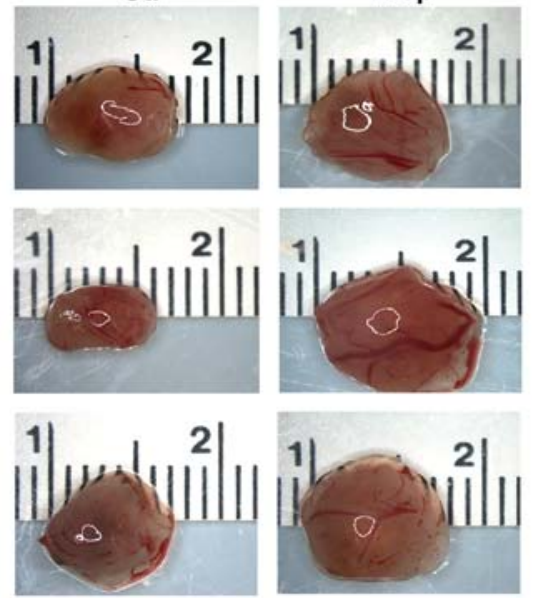

Etop
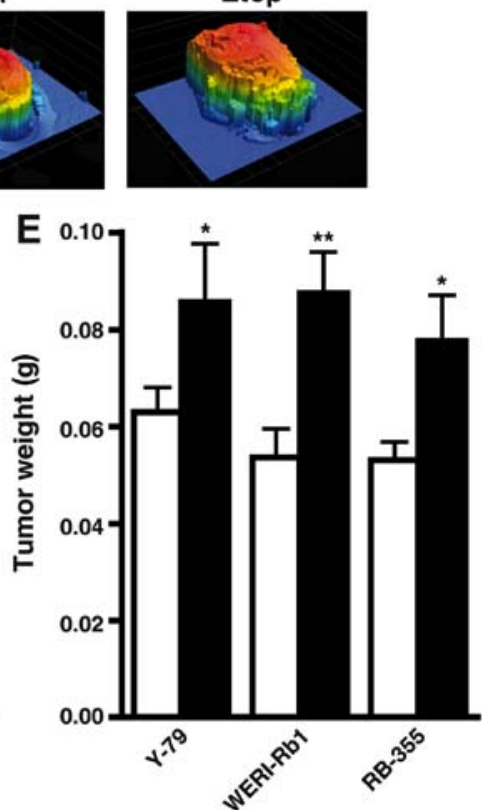

Figure 5. Effects of etoposide resistance on tumor formation capacity of different RB cell lines. (A) Images of tumors in situ (left double column) and of ruler measurements (in $\mathrm{cm}$ ) of excised tumors (right double column) revealed that tumors developing in the upper CAM from grafted etoposide-resistant RB cells (Etop) were significantly larger compared to those arising from control cells (Ctr). (B) Exemplary profiles of excised tumors forming from WERI-RB1 control (Ctr) and etoposide-resistant (Etop) cells visualizing 3-D tumor volume (left double column, natural as excised; right double column, stained by software to indicate different heights). (C) Quantification of tumor formation capacity (D), tumor size (E) and tumor weight (D) revealed that compared to control (Ctr) RB cells at least two out of three etoposide-resistant (Etop) RB cell lines analyzed formed significantly more, bigger and heavier tumors. Legend in C (also applies for $\mathrm{D}$ and $\mathrm{E})$ : white bars, control cells; black bars, etoposide-resistant cells. Values are means from at least 3 independent experiments \pm SEM; " $\mathrm{P}<0.05$,

${ }^{* *} \mathrm{P}<0.01,{ }^{* * *} \mathrm{P}<0.001 ;$ ns, no statistical differences statistical differences compared to the control group calculated by Student's t-test. 


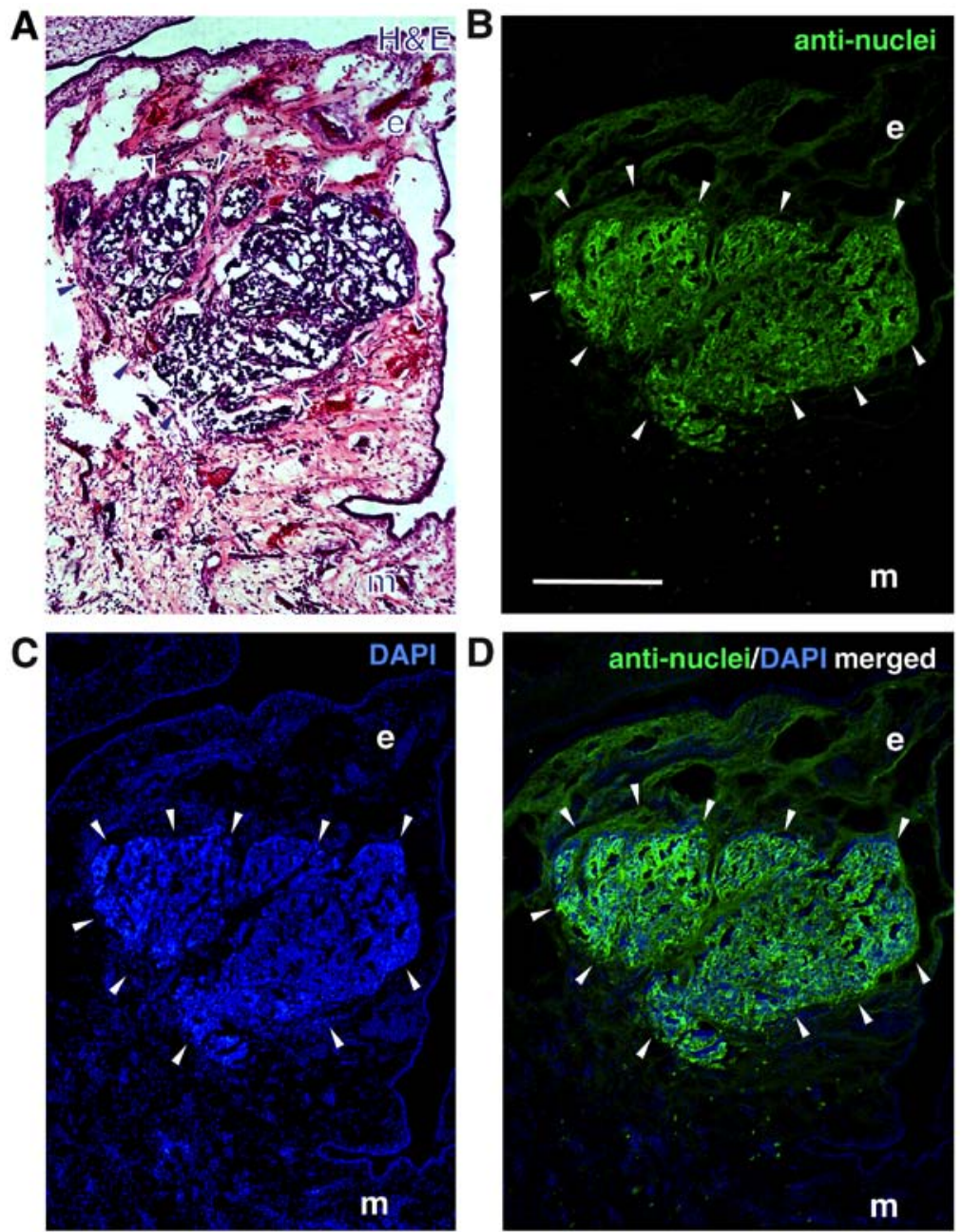

Figure 6. Tumor formation in the chicken CAM. (A) H\&E-stained cryosection of a tumor developing at the border between CAM ectoderm (e) and mesoderm (m) 7 days after grafting human Y-79 control RB cells on the upper chicken CAM. (B) Staining with a human-specific anti-nuclear antibody clearly proved the human RB cell origin of the tumor. (C) DAPI counterstaining. (D) Merged images (green fluorescence, anti-nuclear antibody; blue fluorescence, DAPI) arrowheads, outline of tumor front. Scale bar, $100 \mu \mathrm{m}$ (B, applies to all figures).

mesoderm 7 days after grafting human RB cells was visualized by H\&E staining of tumor cryosections (Fig. 6A). The human nature of the tumors was verified immunocytochemically, using an anti-human nuclear antibody (Fig. 6B-D).

Etoposide resistance significantly affects anchorage independent growth of RB cells. Etoposide resistance changed the anchorage independent growth of Y-79 and WERI-Rb1 cells as reflected by a significant decrease in their colony formation capacity in soft agarose (Fig. 7A). However, all three etoposide-resistant cell lines analyzed formed considerably smaller colonies when compared with the chemosensitive control cells (Fig. 7B).

Cisplatin-resistant RB cell lines display decreased growth and proliferation rates. All cisplatin-resistant cell lines analyzed displayed significantly lower growth kinetics compared to the control cells (Fig. 8A-C). Among the three cisplatin-resistant RB cell lines investigated, Y-79 cells were the slowest in growth and thus, we had to record long-term growth curves over a period of $336 \mathrm{~h}$ (instead of $96 \mathrm{~h}$ ) and plot the values logarithmically to visualize differences between resistant and control cells (Fig. 8A). As revealed by WST-1 assays cisplatin resistance likewise resulted in a significant reduction in cell viability of all three cisplatin-resistant cell lines (Fig. 8D). Cell proliferation was significantly decreased in the Y-79 and WERI-Rb1 cisplatin-resistant RB cell lines as reflected by significantly lower numbers of BrdU-positive cells (Fig. 8E), but remained unchanged in the RB-355 cisplatin-resistant cells (Fig. 8E).

Cisplatin treatment increases apoptosis in resistant $R B$ cell lines. As revealed by DAPI cell counts (Fig. 8F) and confirmed by TUNEL assays (Fig. 4B) cisplatin treatment still significantly increased the apoptosis levels in the cisplatin-resistant $\mathrm{RB}$ cell lines.

Cisplatin significantly influences weight and size of tumors developing from RB cell lines. Photo-documentation (Fig. 9A and $B$ ) and measurements revealed that tumors developing from Y-79 and WERI-Rb1 cisplatin-resistant RB cells were significantly smaller (Fig. 9C). Y-79 cisplatin-resistant cells likewise exhibited significantly lower weights than tumors developing from chemosensitive control cells (Fig. 9D), whereby the same tendency did not reach significance in the WERI-Rb1 cisplatin-resistant cells. Compared to the 


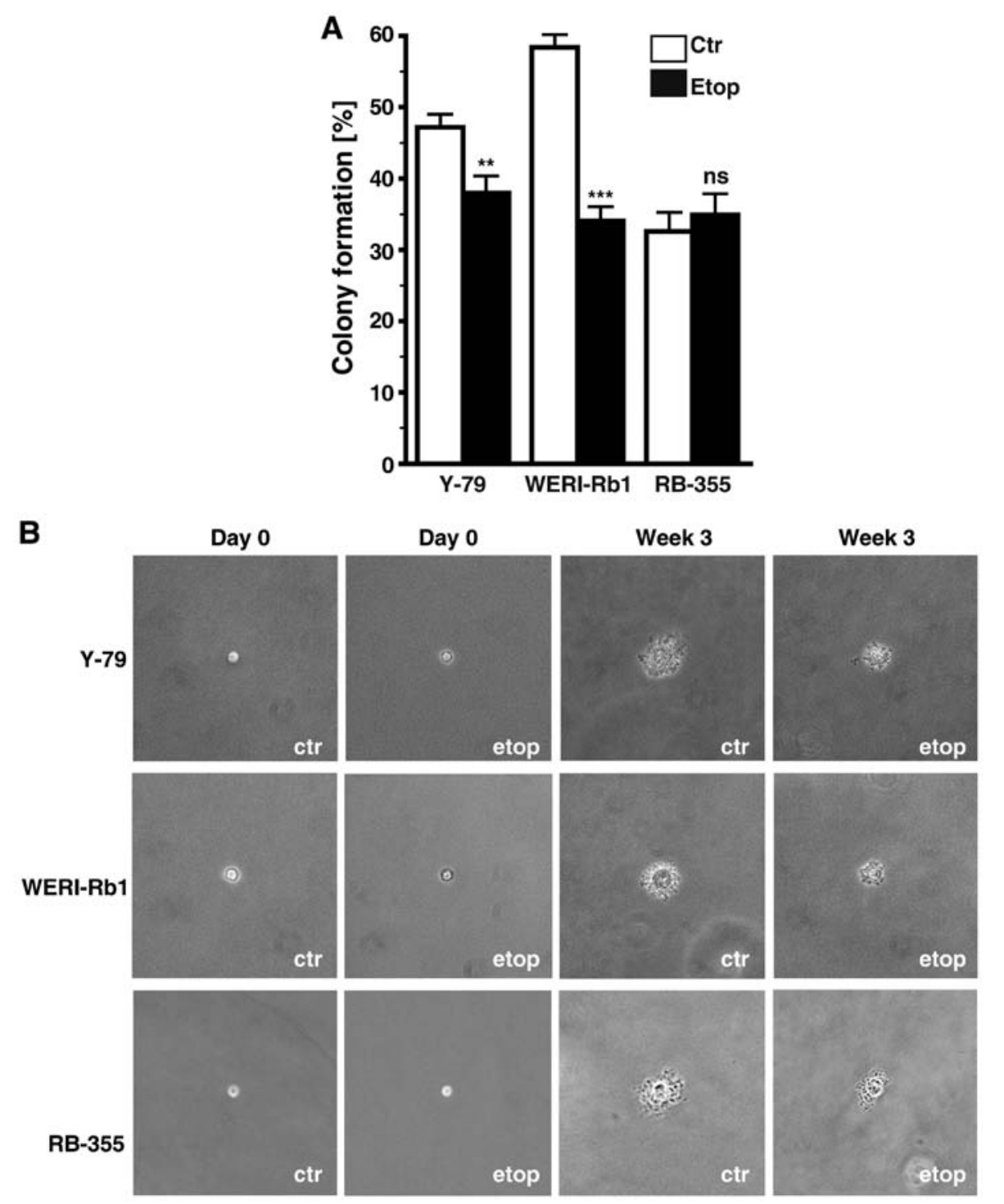

Figure 7. Effect of etoposide resistance on RB cell colony formation capacity. (A) Quantification of soft agarose assays showing a significant lower capacity of etoposide-resistant RB cell lines to form colonies. (B) Images captured from soft agarose colonies at the day of seeding (day 0) and after 3 weeks in culture revealing that etoposide-resistant (Etop) RB cells formed considerably smaller colonies than control cells (Ctr). Values are means from 3 independent experiments $\pm \mathrm{SEM} ;{ }^{* * *} \mathrm{P}<0.01$ compared to the control group calculated by Student's t-test, ${ }^{* * *} \mathrm{P}<0.001$.

respective parental controls, tumors forming from RB-355 cisplatin-resistant cells neither decreased nor increased in size and weight (Fig. 9C and D). Cisplatin resistance did not significantly influence the tumor formation capacity of the three cell lines investigated (data not shown).

Cisplatin resistance significantly effects anchorage independent growth of RB cells. Soft agarose assays revealed that cisplatin resistance significant decreased the colony formation capacity of all cisplatin-resistant RB cell lines analyzed (Fig. 10A). However, all cisplatin-resistant cell lines formed considerably smaller colonies compared to the control cells (Fig. 10B).

\section{Discussion}

Drug resistance and relapse are the major issues associated with chemotherapy, which is regarded as the mainstay of globe preserving treatment in retinoblastoma $(\mathrm{RB})$. In the present study presented, we provide a morphological and functional characterization of three etoposide- and three cisplatinresistant RB cell lines.

Regarding morphological changes, we observed a significant increase in cell and nuclear size in the cisplatin-resistant RB cells, but no significant changes in the etoposide-resistant cells. In this context, Żuryń et al (2016) reported that incubation of HL-60 cells with etoposide resulted in an enlargement of the cells and irregularities in shape (20).

We showed that compared to the cells of origin, etoposideresistant RB cell lines were highly proliferative, displayed a significantly increased tumor formation capacity and formed larger tumors. Thus, these cells obviously become more aggressive than their parental counterparts. Surprisingly, etoposide treatment still induced apoptosis in the etoposide-resistant RB cell lines. In line with our finding, it has been shown that etoposide-resistant melanoma cells likewise display reduced 

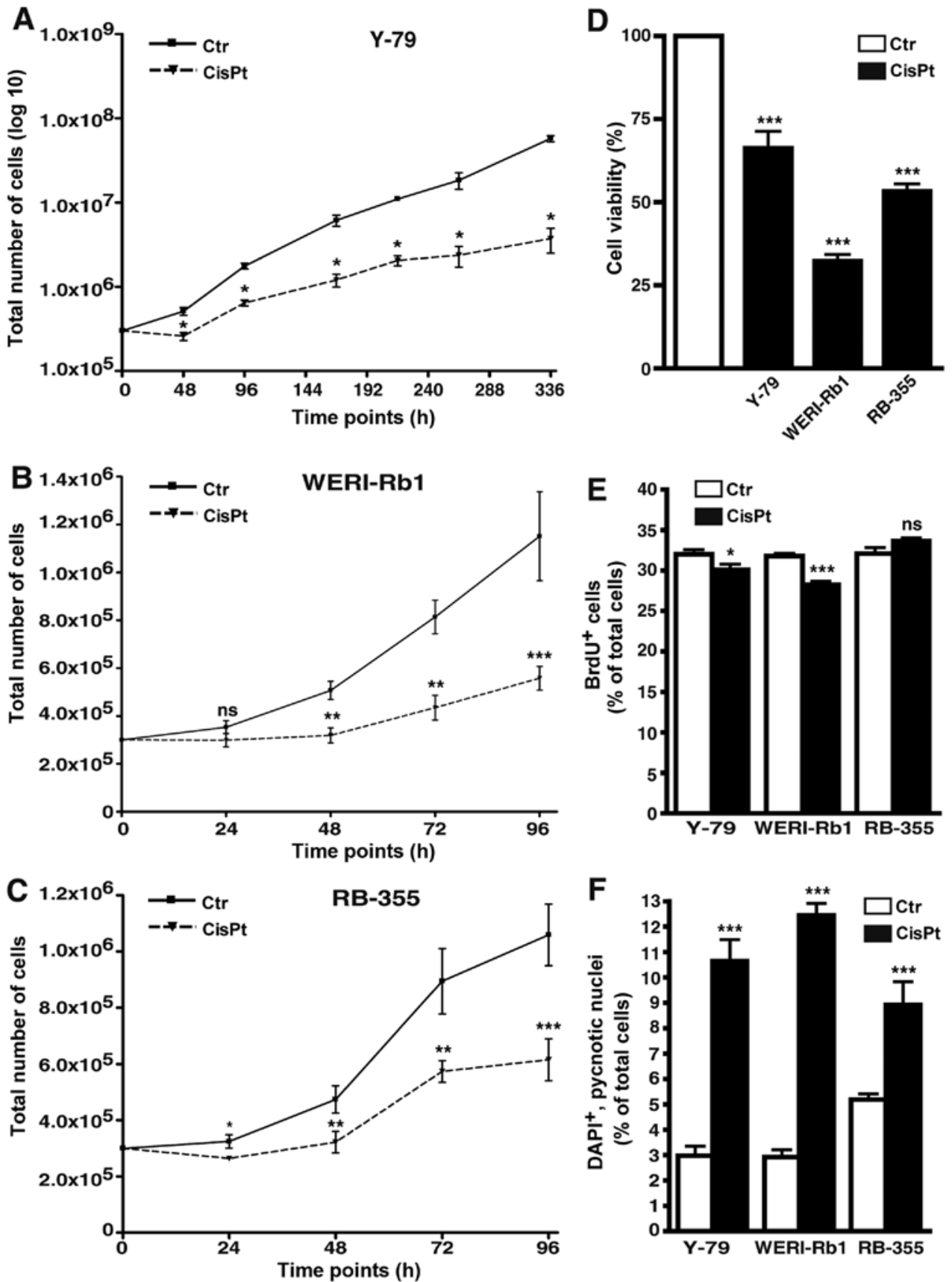

Figure 8. Effects of cisplatin resistance on RB cell growth, viability, proliferation and apoptosis. (A-C) Growth curves, (D) WST-1 assays, (E) BrdU counts and (F) DAPI cell counts of cisplatin-resistant (CisPt) Y-79 (A), WERI-Rb1 (B) and RBL-355 cells (C) vs. control cells (Ctr) revealed that cisplatin resistance led to a significant decrease in growth kinetics (A-C), cell viability (D) and proliferation (E). Cisplatin treatment, however, still significantly increased apoptosis levels in all cisplatin-resistant cell lines (F). Values are means of at least 3 independent experiments $\pm \mathrm{SEM} ;{ }^{*} \mathrm{P}<0.05,{ }^{* * *} \mathrm{P}<0.01,{ }^{* * * *} \mathrm{P}<0.001$ compared to the control group calculated by Student's t-test.

but still detectable apoptotic activities, but activation of the mitochondrial pro-apoptotic pathway was no longer detectable after exposure to etoposide (21).

In contrast to etoposide resistance, we found cisplatin resistance to significantly lower growth kinetics and to induce tumors with equal or diminished weights. Thus, compared to the cells of origin, cisplatin-resistant RB cells do not display increased tumorigenicity and aggressiveness.

Soft agarose assays of the present study presented revealed that etoposide- and cisplatin-resistant RB cell lines exhibited significantly reduced colony formation capacities and formed considerably smaller colonies compared to their parental counterparts. As RB cells normally grow as aggregates (14), the disruption of the united cell structure by single cell seeding in soft agarose seems to be responsible for the failure of chemoresistant RBs to form colonies. Conversely, growth in aggregates is potentially favorable for the development of RB cell chemoresistance. In this context, it has already been shown that cells grown in contact with each other, e.g. as tumor spheroids in culture, are more resistant to alkylating agents and cisplatin than the same cells after disaggregation (22). Moreover, cell growth in aggregates determines 
A
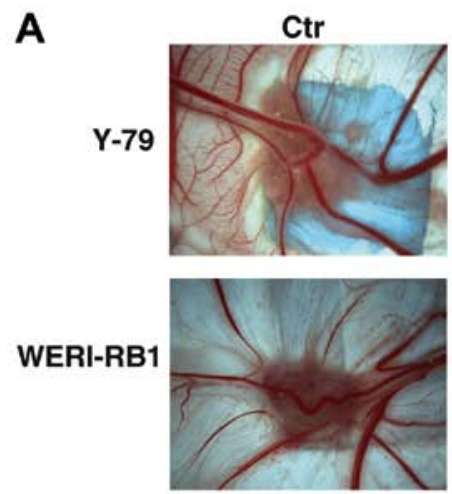

RB-355

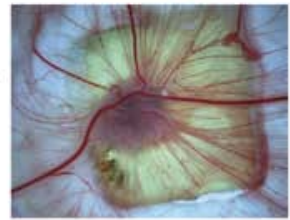

B

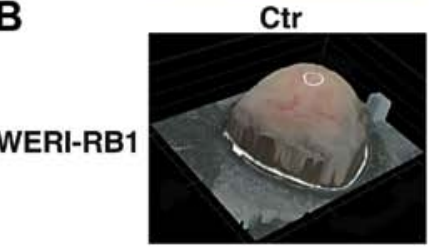

C

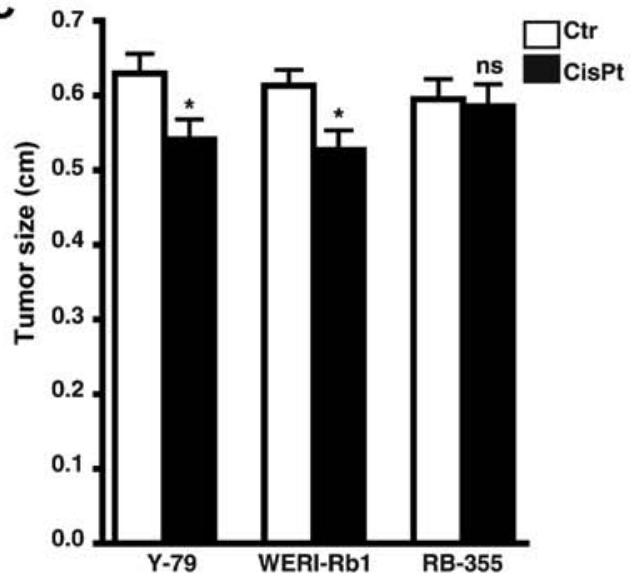

CisPt
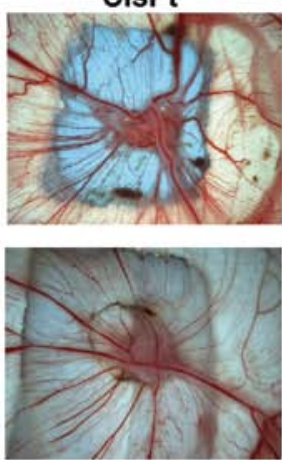

CisPt
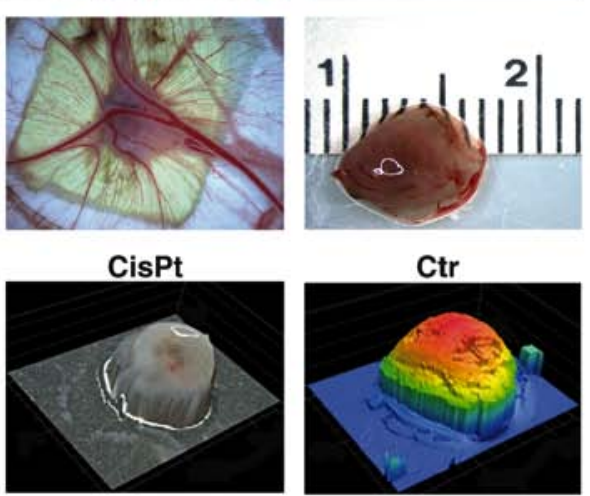

D

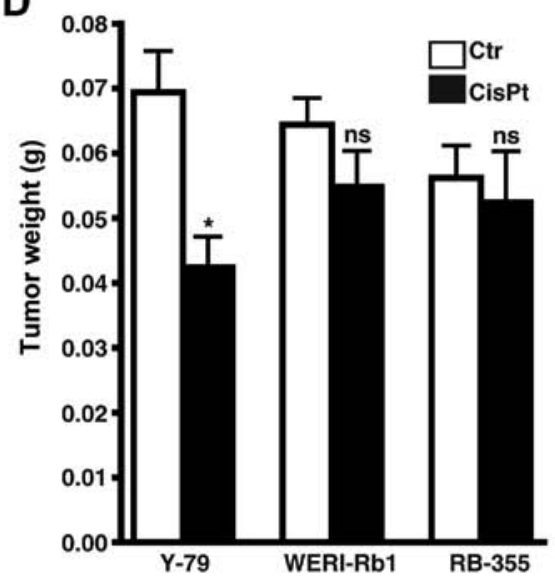

Figure 9. Effects of cisplatin resistance on tumor formation capacity of different RB cell lines. (A) Images of tumors in situ (left double column) and of ruler measurements (in $\mathrm{cm}$ ) of excised tumors (right double column) revealed that tumors developing in the upper CAM from grafted cisplatin-resistant RB cells (CisPt) were smaller compared to those arising from control cells (Ctr). (B) Exemplary profiles of excised tumors forming from WERI-RB1 control (Ctr) and cisplatin-resistant (CisPt) cells visualizing 3-D tumor volume (left double column: natural as excised; right double column, stained by software to indicate different heights). (C and D) Quantification of tumor size (C) and tumor weight (D) revealed that compared to controls (Ctr) Y-79 and WERI-Rb1 cisplatinresistant (CisPt) RB cell lines formed smaller tumors and those of Y-79 cells likewise displayed lighter weight. Values are means from at least 3 independent experiments $\pm \mathrm{SEM} ;{ }^{*} \mathrm{P}<0.05$; ns, no statistical differences statistical differences compared to the control group calculated by Student's t-test.

chemoresistance of follicular lymphoma cells as these cells display resistance to drugs used in lymphoma therapy when cultured in 3 dimensions rather than in suspension (23). Along this line, a number of studies showed that the chemosensitivity of cancer cells is affected by the extent of cell adhesion and expression of intercellular adhesion molecules [reviewed in ref. (24)]. The neuronal L1 cell adhesion molecule (L1CAM) has attracted attention as it is expressed in a variety of tumors and high expression was associated with poor prognosis (25). It has been shown that L1CAM expression confers increased cell growth and tumorigenesis of colorectal cancer cells (26). Further along this line, a combination of anti-L1CAM antibody and cisplatin was found to improve the therapeutic response in cholangiocarcinoma by enhancing tumor growth inhibition compared to treatment with the drug alone (27). Recently, Jo et al showed that L1CAM increased the adhesion-mediated proliferation and resistance of Y-79 and SNUOT-Rb1 RB cells to carboplatin, vincristine and etoposide (28).

Among other mechanisms, ATP-binding cassette (ABC) transporters were found to contribute to the process of drug resistance in cancer $(29,30)$ as overexpression of these drug transporters in tumor cells reduces the intracellular drug level by increasing its efflux (31). Kachalaki et al found that ABCB1 [multi-drug resistance (MDR) P-glycoprotein/ MDR1] may 

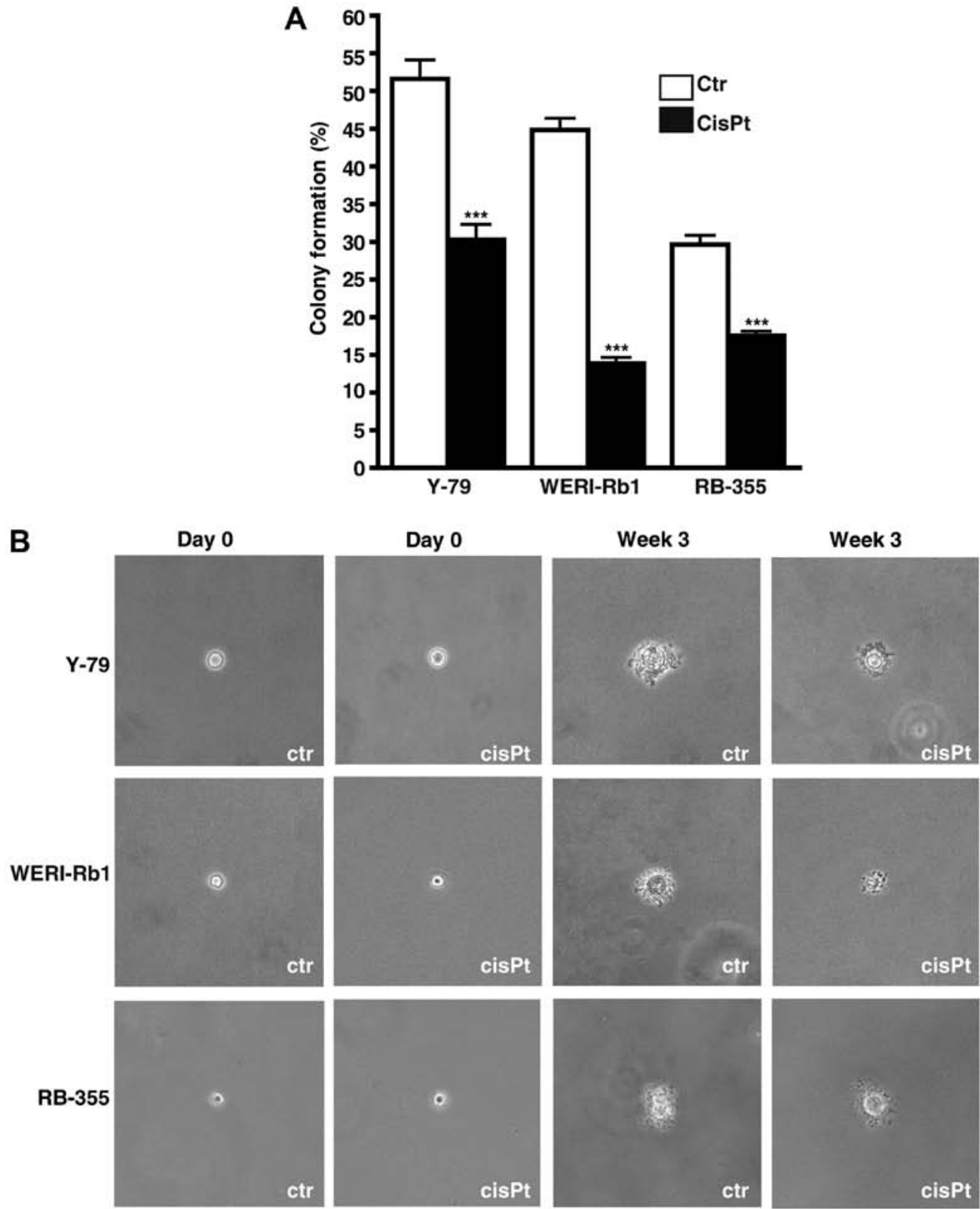

Figure 10. Effect of cisplatin resistance on RB cell colony formation capacity. (A) Quantification of soft agarose assays showing a significant lower capacity of cisplatin-resistant RB cell lines to form colonies. (B) Images taken from soft agarose colonies at the day of seeding (day 0) and after 3 weeks in culture revealed that cisplatin-resistant (CisPt) RB cells formed considerably smaller colonies than control cells (Ctr). Values are means from 3 independent experiments \pm SEM; ${ }^{* * *} \mathrm{P}<0.001$ compared to the control group calculated by Student's t-test.

play a role in acute myeloid leukemia cell resistance to etoposide (32). However, the overexpression of ABCB1 reduced the sensitivities of ovarian cancer lines to cisplatin (33). In RB the expression of P-glycoprotein has likewise been linked to chemotherapy resistance (34-36). Recently, it has been shown that silencing of the ATP-binding cassette subfamily $G$ member 2 (ABCG2) inhibits multidrug resistance of WERI$\mathrm{Rb} 1 \mathrm{RB}$ cancer stem cells, including their resistance to etoposide and cisplatin treatment (37).

Hypoxic tumor microenvironment is another factor that determines the therapeutic response in many tumors. It has been shown that hypoxia attenuates etoposide mediated G2/M arrest and apoptosis induction and thus promotes etoposide resistance in neuroblastoma cells (38).
Sudhakar et al found no expression of hypoxia-inducible factor-1 $\alpha(\mathrm{HIF}-1 \alpha)$ in the normal adult retina, but observed positive HIF-1 $\alpha$ immunoreactivity in $83 \%$ RB tumors analyzed (39). Along this line, brain-derived neurotrophic factor (BDNF) protects RB cells from chemotherapy-induced apoptosis and thereby contribute to their chemoresistance via induction of HIF-1 $\alpha$ expression (40).

It has been reported that clusterin, a cytoprotective chaperone protein known to protect various retinal cells, is overexpressed in several types of malignant tumors. Song et al found clusterin to be expressed in human RB and to exert antiapoptotic effects on cisplatin-induced apoptosis and prevent cell death. Therefore, the authors hypothesized that clusterin can contribute to cisplatin resistance of RB (41). 
Finally, microRNAs (miRNAs) have been identified to directly or indirectly influence the development of cancer drug resistance [for review see $(42,43)$ ]. In this regard, Jia et al recently showed that after overexpression of miR-3163 etoposide and cisplatin resistance of RB cancer stem cells significantly decline (37).

After a first, more descriptive functional characterization in the present study, ongoing experiments may address the question of which mechanisms underlie the development of etoposide and cisplatin resistance in RB cell lines and how these can be circumvented. Currently, one can state that etoposide-resistant RB cells display therapeutically undesirable features such as fast growth, high proliferation rate and a significantly increased tumor formation capacity compared to the tumor cells of origin. Thereby, etoposide resistance seems to aggravate the course of the disease and potentially worsens patient prognosis. By contrast, compared to their parental counterparts, cisplatin-resistant RB cells continue to exhibit higher apoptosis rates, decreased growth kinetics and equal or diminished tumor weights. It takes an extended treatment period to induce cisplatin resistance and cisplatin-resistant RB cells do not display more aggressive features than the cells of origin. Thus, finally cisplatin resistance has less severe consequences for RB patients.

\section{References}

1. Yousef YA, Soliman SE, Astudillo PPP, Durairaj P, Dimaras H, Chan HSL, Héon E, Gallie BL and Shaikh F: Intra-arterial chemotherapy for retinoblastoma: a systematic review. JAMA Ophthalmol: Mar 17, 2016 (Epub ahead of print). doi: 10.1001/jamaophthalmol.2016.0244.

2. Shields CL, Lally SE, Leahey AM, Jabbour PM, Caywood EH, Schwendeman R and Shields JA: Targeted retinoblastoma management: When to use intravenous, intra-arterial, periocular, and intravitreal chemotherapy. Curr Opin Ophthalmol 25: 374-385, 2014

3. Abramson DH, Shields CL, Munier FL and Chantada GL: Treatment of retinoblastoma in 2015: Agreement and disagreement. JAMA Ophthalmol 133: 1341-1347, 2015.

4. Beck WT, Mo YY and Bhat UG: Cytotoxic signalling by inhibitors of DNA topoisomerase II. Biochem Soc Trans 29: 702-703, 2001

5. Clifford B, Beljin M, Stark GR and Taylor WR: $G_{2}$ arrest in response to topoisomerase II inhibitors: The role of p53. Cancer Res 63: 4074-4081, 2003

6. Yuan L, Yu WM and Qu CK: DNA damage-induced $\mathrm{G}_{2} / \mathrm{M}$ checkpoint in SV40 large T antigen-immortalized embryonic fibroblast cells requires SHP-2 tyrosine phosphatase. J Biol Chem 278: 42812-42820, 2003

7. Villegas VM, Hess DJ, Wildner A, Gold AS and Murray TG: Retinoblastoma. Curr Opin Ophthalmol 24: 581-588, 2013.

8. Griegel S, Hong C, Frötschl R, Hülser DF, Greger V, Horsthemke B and Rajewsky MF: Newly established human retinoblastoma cell lines exhibit an 'immortalized' but not an invasive phenotype in vitro. Int J Cancer 46: 125-132, 1990.

9. Reid TW, Albert DM, Rabson AS, Russell P, Craft J, Chu EW, Tralka TS and Wilcox JL: Characteristics of an established cell line of retinoblastoma. J Natl Cancer Inst 53: 347-360, 1974.

10. McFall RC, Sery TW and Makadon M: Characterization of a new continuous cell line derived from a human retinoblastoma. Cancer Res 37: 1003-1010, 1977.

11. Stephan H, Boeloeni R, Eggert A, Bornfeld N and Schueler A: Photodynamic therapy in retinoblastoma: Effects of verteporfin on retinoblastoma cell lines. Invest Ophthalmol Vis Sci 49: 3158-3163, 2008.

12. Haubold M, Weise A, Stephan H and Dünker N: Bone morphogenetic protein 4 (BMP4) signaling in retinoblastoma cells. Int J Biol Sci 6: 700-715, 2010 .
13. Philippeit $\mathrm{C}$, Busch $\mathrm{M}$ and Dünker N: Epigenetic control of trefoil factor family (TFF) peptide expression in human retinoblastoma cell lines. Cell Physiol Biochem 34: 1001-1014, 2014.

14. Busch M,Philippeit C, Weise A andDünkerN:Re-characterization of established human retinoblastoma cell lines. Histochem Cell Biol 143: 325-338, 2015.

15. Zijlstra A, Mellor R, Panzarella G, Aimes RT, Hooper JD, Marchenko ND and Quigley JP: A quantitative analysis of ratelimiting steps in the metastatic cascade using human-specific real-time polymerase chain reaction. Cancer Res 62: 7083-7092, 2002.

16. Palmer TD, Lewis $\mathrm{J}$ and Zijlstra A: Quantitative analysis of cancer metastasis using an avian embryo model. J Vis Exp 51: $2815,2011$.

17. Weise A and Dünker N: High trefoil factor 1 (TFF1) expression in human retinoblastoma cells correlates with low growth kinetics, increased cyclin-dependent kinase (CDK) inhibitor levels and a selective down-regulation of CDK6. Histochem Cell Biol 139: 323-338, 2013.

18. Elso CM, Roberts LJ, Smyth GK, Thomson RJ, Baldwin TM, Foote SJ and Handman E: Leishmaniasis host response loci (lmrl-3) modify disease severity through a Th1/Th2-independent pathway. Genes Immun 5: 93-100, 2004.

19. Busch M and Dünker N: Trefoil factor family peptides - friends or foes? Biomol Concepts 6: 343-359, 2015.

20. Żuryń A, Krajewski A, Szulc D, Litwiniec A and Grzanka A: Activity of cyclin B1 in HL-60 cells treated with etoposide. Acta Histochem 118: 537-543, 2016.

21. Helmbach H, Kern MA, Rossmann E, Renz K, Kissel C, Gschwendt B and Schadendorf D: Drug resistance towards etoposide and cisplatin in human melanoma cells is associated with drug-dependent apoptosis deficiency. J Invest Dermatol 118: 923-932, 2002

22. Kerbel RS, St Croix B, Florenes VA and Rak J: Induction and reversal of cell adhesion-dependent multicellular drug resistance in solid breast tumors. Hum Cell 9: 257-264, 1996.

23. Gravelle P, Jean C, Familiades J, Decaup E, Blanc A, Bezombes-Cagnac C, Laurent C, Savina A, Fournié JJ and Laurent G: Cell growth in aggregates determines gene expression, proliferation, survival, chemoresistance, and sensitivity to immune effectors in follicular lymphoma. Am J Pathol 184: 282-295, 2014

24. St Croix B and Kerbel RS: Cell adhesion and drug resistance in cancer. Curr Opin Oncol 9: 549-556, 1997.

25. Fogel M, Gutwein P, Mechtersheimer S, Riedle S, Stoeck A, Smirnov A, Edler L, Ben-Arie A, Huszar M and Altevogt P: L1 expression as a predictor of progression and survival in patients with uterine and ovarian carcinomas. Lancet 362: 869-875, 2003.

26. Gavert N, Conacci-Sorrell M, Gast D, Schneider A, Altevogt P, Brabletz T and Ben-Ze'ev A: L1, a novel target of beta-catenin signaling, transforms cells and is expressed at the invasive front of colon cancers. J Cell Biol 168: 633-642, 2005.

27. Cho S, Lee TS, Song IH, Kim AR, Lee YJ, Kim H, Hwang H, Jeong MS, Kang SG and Hong HJ: Combination of anti-L1 cell adhesion molecule antibody and gemcitabine or cisplatin improves the therapeutic response of intrahepatic cholangiocarcinoma. PLoS One 12: e0170078, 2017.

28. Jo DH, Lee K, Kim JH, Jun HO, Kim Y, Cho YL, Yu YS, Min JK and Kim JH: L1 increases adhesion-mediated proliferation and chemoresistance of retinoblastoma. Oncotarget 8: 15441-15452, 2017.

29. Szakács G, Paterson JK, Ludwig JA, Booth-Genthe C and Gottesman MM: Targeting multidrug resistance in cancer. Nat Rev Drug Discov 5: 219-234, 2006.

30. Longley DB and Johnston PG: Molecular mechanisms of drug resistance. J Pathol 205: 275-292, 2005.

31. Wu CP, Calcagno AM and Ambudkar SV: Reversal of ABC drug transporter-mediated multidrug resistance in cancer cells: Evaluation of current strategies. Curr Mol Pharmacol 1: 93-105, 2008.

32. Kachalaki S, Baradaran B, Majidi J, Yousefi M, Shanehbandi D, Mohammadinejad S and Mansoori B: Reversal of chemoresistance with small interference RNA (siRNA) in etoposide resistant acute myeloid leukemia cells (HL-60). Biomed Pharmacother 75: 100-104, 2015.

33. Wu DD, Li XS, Meng XN, Yan J and Zong ZH: MicroRNA-873 mediates multidrug resistance in ovarian cancer cells by targeting ABCB1. Tumour Biol 37: 10499-10506, 2016. 
34. Chan HS, Thorner PS, Haddad G and Gallie BL: Multidrugresistant phenotype in retinoblastoma correlates with P-glycoprotein expression. Ophthalmology 98: 1425-1431, 1991.

35. Chan HS, Lu Y, Grogan TM, Haddad G, Hipfner DR, Cole SP, Deeley RG, Ling V and Gallie BL: Multidrug resistance protein (MRP) expression in retinoblastoma correlates with the rare failure of chemotherapy despite cyclosporine for reversal of P-glycoprotein. Cancer Res 57: 2325-2330, 1997.

36. Filho JPS, Correa ZM, Odashiro AN, Coutinho AB, Martins MC, Erwenne CM and Burnier MN Jr: Histopathological features and P-glycoprotein expression in retinoblastoma. Invest Ophthalmol Vis Sci 46: 3478-3483, 2005.

37. Jia M, Wei Z, Liu P and Zhao X: Silencing of ABCG2 by microRNA-3163 inhibits multidrug resistance in retinoblastoma cancer stem cells. J Korean Med Sci 31: 836-842, 2016.

38. Wang D, Zhu Q, Zhang X, Zhang L, He Q and Yang B: Hypoxia promotes etoposide (VP-16) resistance in neuroblastoma CHP126 cells. Pharmazie 65: 51-56, 2010.
39. Sudhakar J, Venkatesan N, Lakshmanan S, Khetan V, Krishnakumar S and Biswas J: Hypoxic tumor microenvironment in advanced retinoblastoma. Pediatr Blood Cancer 60: 1598-1601, 2013.

40. Gao Y, Jing M, Ge R and Lang L: Induction of hypoxia-inducible factor-1 $\alpha$ by BDNF protects retinoblastoma cells against chemotherapy-induced apoptosis. Mol Cell Biochem 414: 77-84, 2016.

41. Song HB, Jun HO, Kim JH, Yu YS, Kim KW, Min BH and Kim JH: Anti-apoptotic effect of clusterin on cisplatin-induced cell death of retinoblastoma cells. Oncol Rep 30: 2713-2718, 2013.

42. Magee P, Shi L and Garofalo M: Role of microRNAs in chemoresistance. Ann Transl Med 3: 332, 2015.

43. Ayers D and Vandesompele J: Influence of microRNAs and long non-coding RNAs in cancer chemoresistance. Genes 8: pii: E95, 2017.

This work is licensed under a Creative Commons Attribution-NonCommercial-NoDerivatives 4.0 International (CC BY-NC-ND 4.0) License. 